Article

\title{
Implementing a Substance-Use Screening and Intervention Program for People Living with Rifampicin-Resistant Tuberculosis: Pragmatic Experience from Khayelitsha, South Africa
}

\author{
Anja Reuter ${ }^{1}$, , Buci Beko ${ }^{1}$, Boniwe Memani ${ }^{1}$, Jennifer Furin ${ }^{2}$, Johnny Daniels ${ }^{1}$, Erickmar Rodriguez ${ }^{1}$, \\ Hermann Reuter ${ }^{3}$, Lize Weich ${ }^{4}$, Petros Isaakidis ${ }^{5}$, Erin von der Heyden ${ }^{6}$, Yulene Kock ${ }^{7}$ \\ and Erika Mohr-Holland 1,5
}

\section{check for}

updates

Citation: Reuter, A.; Beko, B.;

Memani, B.; Furin, J.; Daniels, J.; Rodriguez, E.; Reuter, H.; Weich, L.; Isaakidis, P.; von der Heyden, E.; et al. Implementing a Substance-Use Screening and Intervention Program for People Living with Rifampicin-Resistant Tuberculosis: Pragmatic Experience from Khayelitsha, South Africa. Trop. Med. Infect. Dis. 2022, 7, 21. https:// doi.org/10.3390/tropicalmed7020021

Academic Editors: Tapash Roy, Amyn A. Malik, Abu Naser Zafar Ullah and Sourya Shrestha

Received: 27 December 2021

Accepted: 28 January 2022

Published: 31 January 2022

Publisher's Note: MDPI stays neutral with regard to jurisdictional claims in published maps and institutional affiliations.

Copyright: (C) 2022 by the authors. Licensee MDPI, Basel, Switzerland. This article is an open access article distributed under the terms and conditions of the Creative Commons Attribution (CC BY) license (https:// creativecommons.org/licenses/by/ $4.0 /)$.
1 Médecins Sans Frontières, Khayelitsha 7784, South Africa; msfocb-khayelitsha-tbconsl@brussels.msf.org (B.B.); MSFOCB-khayelitsha-psu@brussels.msf.org (B.M.); MSFOCB-Khayelitsha-Tbdata@brussels.msf.org (J.D.); psi.mar.rodriguez@gmail.com (E.R.); mohrek27@gmail.com or msfocb-khayelitsha-drtb-epi@brussels.msf.org (E.M.-H.)

2 Department of Global Health and Social Medicine, Harvard Medical School, Boston, MA 02115, USA; jenniferfurin@gmail.com

3 Faculty of Health Sciences, University of Cape Town, Cape Town 7701, South Africa; hermannreuter@gmail.com

4 Department of Psychiatry, Faculty of Medicine and Health Sciences, Stellenbosch University, Cape Town 7701, South Africa; lizew@sun.ac.za

5 Médecins Sans Frontières Southern Africa Medical Unit, Cape Town 7925, South Africa; Petros.Isaakidis@joburg.msf.org

6 Provincial Government of the Western Cape, Cape Town 8000, South Africa; Erin.vonderHeyden@westerncape.gov.za

7 National Department of Health Tuberculosis Program, Pretoria 0187, South Africa; Yulene.Kock@health.gov.za

* Correspondence: msfocb-khayelitsha-tbdoc@brussels.msf.org

\begin{abstract}
Substance use (SU) is associated with poor rifampicin-resistant tuberculosis (RR-TB) treatment outcomes. In 2017, a SBIRT (SU screening-brief intervention-referral to treatment) was integrated into routine RR-TB care in Khayelitsha, South Africa. This was a retrospective study of persons with RR-TB who were screened for SU between 1 July 2018 and 30 September 2020 using the ASSIST (Alcohol, Smoking and Substance Involvement Screening Test). Here we describe outcomes from this program. Persons scoring moderate/high risk received a brief intervention and referral to treatment. Overall, 333 persons were initiated on RR-TB treatment; 38\% $(n=128)$ were screened for SU. Of those, $88 \%(n=113 / 128)$ reported SU; $65 \%(n=83 / 128)$ had moderate/high risk SU. Eighty percent $(n=103 / 128)$ reported alcohol use, of whom $52 \%(n=54 / 103)$ reported moderate/high risk alcohol use. Seventy-seven persons were screened for SU within $\leq 2$ months of RR-TB treatment initiation, of whom $69 \%, 12 \%$, and $12 \%$ had outcomes of treatment success, loss to follow-up and death, respectively. Outcomes did not differ between persons with no/low risk and moderate/high risk SU or based on the receipt of naltrexone $(p>0.05)$. SU was common among persons with RR-TB; there is a need for interventions to address this co-morbidity as part of "person-centered care". Integrated, holistic care is needed at the community level to address unique challenges of persons with RR-TB and SU.
\end{abstract}

Keywords: RR-TB; substance use; integrated care; person-centered care; loss-to-follow-up; ASSIST; brief intervention; SBIRT

\section{Introduction}

Rifampicin-resistant tuberculosis (RR-TB) affects half a million people each year and is associated with a high rate of morbidity and mortality [1]. Although there have been 
recent therapeutic improvements leading to better treatment outcomes, global success rates are just over $61 \%$ [2]. Treatment for RR-TB is characterized by a long duration and high pill burden, and multiple patients are unable to adhere to this grueling therapy or complete the prescribed course of treatment [3-6]. People who stop taking treatment early or who miss more than 8 weeks of therapy are given an outcome of Loss to Follow-Up (LTFU). Rates of LTFU vary considerably between settings and are driven by multiple factors, including the use of alcohol and other substances [7-9].

Substance-use disorder (SUD) is a common co-morbid condition among people living with RR-TB. It is a risk for poor treatment outcomes, including LTFU [10]. Substance use (SU) also complicates other aspects of RR-TB treatment including overlapping toxicities with TB treatment [11], increased experiences of stigma, and lack of access to SU treatment given the infectious nature of RR-TB.

The World Health Organization (WHO) has recommended that health service providers offer screening and interventions for SU within a framework called Screening, Brief Intervention, and Referral to Treatment or SBIRT [12]. The WHO also recommends naltrexone [13], an opioid-receptor blocker that has been shown to reduce alcohol use and decrease the risk of relapse [14], be offered as a pharmacotherapeutic option for persons with an alcohol use disorder. Given the high rates of SU seen among people with RR-TB and the potential health consequences of such use, both a SBIRT model and access to naltrexone for persons with alcohol use disorder could be helpful to integrate into outpatient RR-TB care. In 2017, the medical humanitarian organization Médecins Sans Frontières (MSF) implemented a pilot SBIRT program in collaboration with the Department of Health for people living with RR-TB in Khayelitsha, South Africa. Here we aim to describe the results of this pilot program by describing SU screening, screening scores, and RR-TB treatment outcomes for persons screened for SU within 2 months of treatment initiation.

\section{Materials and Methods}

\subsection{Study Design and Participants}

This was a retrospective cohort study of people treated for RR-TB in Khayelitsha, South Africa between 1 July 2018 and 30 September 2020. Persons were considered eligible for the cohort study if they were initiated on RR-TB treatment during that time period and if they underwent an initial screening for SU at any time during the treatment. Only those individuals who underwent screening within the initial 2 months of RR-TB treatment were included in the treatment outcome analysis in order to assess the potential impact of a timely SBIRT intervention on treatment response.

\subsection{Setting}

This study was conducted in Khayelitsha, a peri-urban township located on the outskirts of Cape Town (in the Western Cape province) which is home to approximately 400,000 residents, a majority of whom live in poverty [15]. TB, RR-TB, and HIV are significant health problems in the population; the RR-TB case notification rate is 55/100,000/year, and approximately 70\% of RR-TB patients are HIV co-infected [16]. A survey conducted by the Western Cape Government describes that $62 \%$ of Khayelitsha residents drink alcohol, with $42 \%$ having had contact with police in the previous 6 months due to alcohol use [17]. Reported rates of illicit substances such as TIK (crystal methamphetamines), MANDRAX (250 mg methaqualone and $25 \mathrm{mg}$ diphenhydramine), and "woonga" (a heroin-based cocktail drug) are the highest in South Africa with $7.1 \%$ of respondents from the Western Cape reporting previous illicit drug use in the past 3 months in a population survey [18]. MSF has been supporting the Department of Health in the decentralized management of RR-TB in 10 health clinics in Khayelitsha, South Africa for more than 10 years. LTFU remains a significant challenge ranging from 20-25\% in Khayelitsha since 2017, despite implementation of shorter treatment regimens. 


\subsection{Screening, Brief Intervention, and Referral to Treatment (SBIRT) Description}

The SBIRT package, summarized in Figure 1, was integrated into routine primary health care clinic visits; it was usually conducted within a single clinic visit, although sometimes two if requested by the patient, and it was most commonly administered by a trained lay RR-TB counselor. For some individual patients it was administered by the doctor or nurse working in the TB room. Training and mentoring on the screening and brief intervention tool was provided by MSF staff to RR-TB counselors, as well as to TB doctors and nurses. Most department of health staff also received motivational interviewing training facilitated by MSF through an external partner. In addition to training and mentoring, MSF provided additional human resources to support the program at the 10 clinics with an MSF RR-TB counselor, and for a shorter period of time with an MSF nurse.

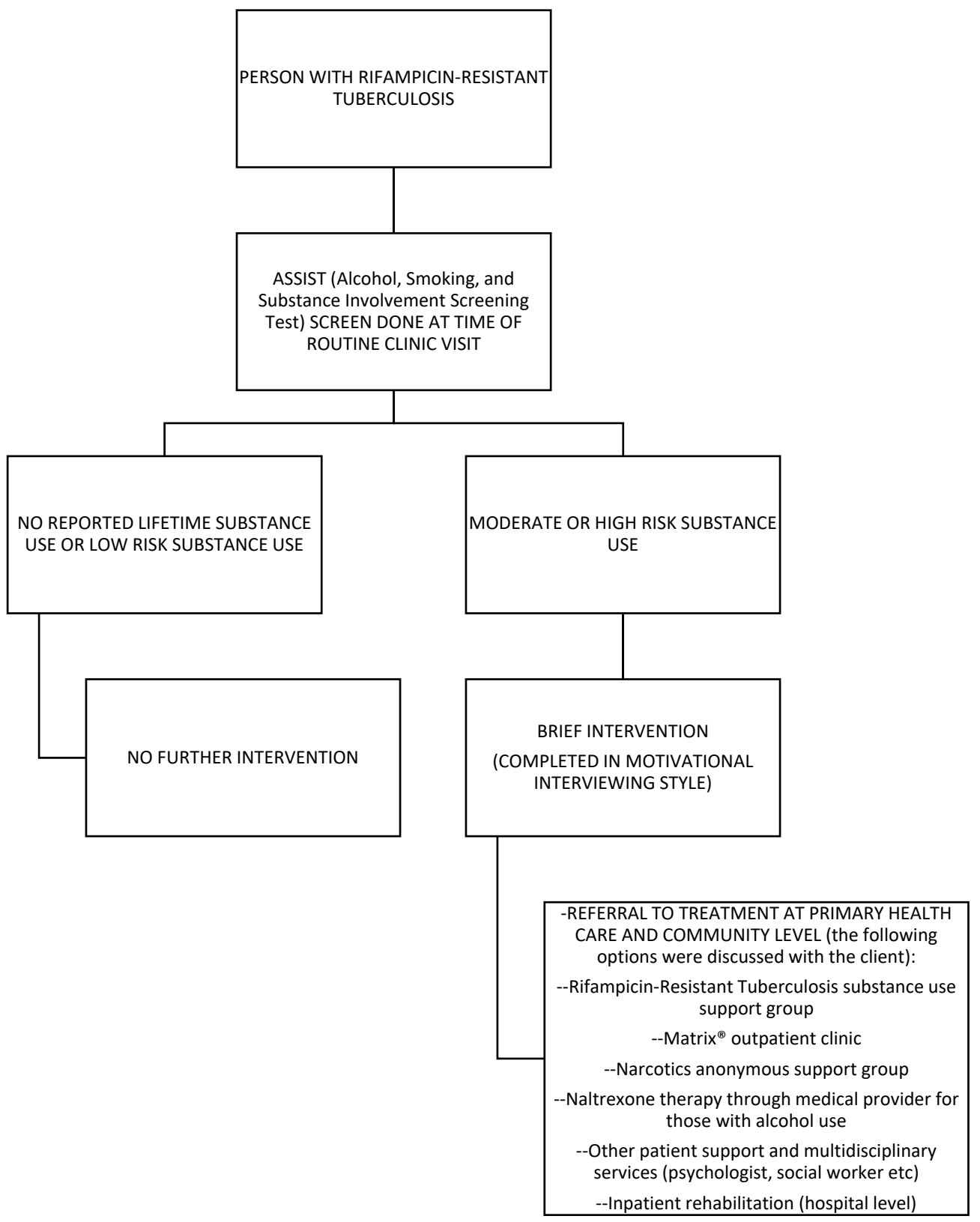

Figure 1. Rifampicin-resistant tuberculosis substance-use intervention flow diagram (Screening, Brief Intervention and Referral to Treatment Model). This intervention could be implemented by doctors, nurses, or trainer lay counselors at primary health care facility. 


\subsubsection{Screening}

The screening component of the SBIRT was done using Alcohol, Smoking and Substance Involvement Screening Test (ASSIST) [12]. An overall SU score is given as a score for each individual substance assessed. Notably, as part of this intervention, if a person reported on the initial question that they had "never" used any substances in their lifetimes, then no additional screening questions were asked. Persons who reported no lifetime SU, or scored low risk for SU received no further intervention. Persons who scored moderate or high risk received a brief intervention and referral to treatment.

\subsubsection{Brief Intervention}

The brief intervention was based on the WHO ASSIST linked brief intervention [12], however the intervention was tailored to persons with HIV / TB.

\subsubsection{Referral/Treatment}

The referral/treatment component included multiple aspects. First, people were provided with information and facilitated access (including transport) to a RR-TB specific SU support group and the City of Cape Town Matrix ${ }^{\circledR}$ outpatient rehabilitation program. Second, details of the Khayelitsha Narcotics Anonymous group and the contact details of a RR-TB counselor experienced in SU counseling were shared (both verbally and in health information and educational materials). Third, persons thought to require inpatient rehabilitation support were referred to the doctor to discuss RR-TB care at the central hospital, where an inpatient SU program was available. Finally, persons using alcohol were offered the opportunity to see a medical practitioner for naltrexone pharmacotherapy initiation.

Naltrexone was offered to all patients who had moderate or high-risk alcohol use, and who did not have a medical contra-indication to its use. Therapy was initiated if the patient expressed a goal to reduce the use of alcohol and if they indicated that they wanted to start therapy. Initially, patients were issued a 1-month supply. Although counseling was provided that the ideal way of taking medication was daily, the "Sinclair method" was proposed as an alternative [19]. This method entails the use of naltrexone at times when the risk of drinking is high-for example, at weekends.

\subsection{Follow Up Care}

During the follow-up clinical RR-TB visits post-SBIRT implementation, discussions around SU using the motivational interviewing techniques could continue between the TB care provider and the patient in order to increase motivation to reduce harmful SU.

\subsection{Outcome Measures and Definitions}

Patients were defined as never using substances if they reported that they never used alcohol, tobacco, and drugs in their lifetime. Persons who reported ever using substances were given a risk score (low, moderate, or high risk) for each substance of use according to the criteria outlined in the ASSIST [12]. Persons were given an overall risk classification defined as the highest risk classification reported for a single substance of use for each person (some persons reported high risk use of multiple substances). RR-TB treatment outcomes were defined according to the standard WHO definitions [20]; cure and treatment completed were combined as treatment success.

\subsection{Data Collection and Analysis}

Data were obtained from the South African Electronic Drug-Resistant Tuberculosis Register (EDRWeb), paper RR-TB registers, and patients' medical records, where the ASSIST and brief intervention tools were recorded. Data entered in EDRWeb were validated using information in patient medical records and RR-TB registers. Data on SU screening included the following variables: date of SU screening, SU screening results (substance/s of use and risk classification scores), date of the brief intervention, whether naltrexone was initiated, and if the patient experienced any serious adverse event while on naltrexone therapy. These 
data were entered into a RedCap Database [21] and linked to the routine programmatic data collected from exports from the routine monitoring systems.

Population comparisons for baseline clinical and demographic variables were compared using chi square and Fisher and Wilcoxon rank-sum tests. For stratified analyses based on overall SU risk, patients were grouped as having no- or low-risk SU and moderateor high-risk $\mathrm{SU}$ as this determined who had access to a brief intervention and referral to treatment. Categorical variables are presented as numbers and proportions and continuous variables are presented as medians and interquartile ranges. Descriptive statistics were used to report on the SU screening cascade, including risk scores for substances used and referral to pharmacotherapy, and RR-TB treatment outcomes. RR-TB outcomes for persons screened for SU within less than or equal to 2 months of RR-TB treatment initiation were reported stratified by no/low risk SU versus moderate/high risk SU. Finally, for persons with moderate- and high-risk alcohol use who were screened for SU within less than or equal to 2 months of RR-TB treatment initiation, RR-TB outcomes were reported stratified by receipt of naltrexone. $p$-values $<0.05$ were considered statistically significant.

\subsection{Ethics}

Ethical approval was obtained from the University of Cape Town Human Research Ethics Committee (HREC 499/2011) for this study. Additionally, this research fulfilled the exemption criteria set by the MSF Ethical Review Board for a posterior analysis of routinely collected clinical data and thus did not require MSF ERB review.

\section{Results}

\subsection{Clinical and Demographic Characteristics Based on Substance-Use (SU) Screening}

Over the study period, 333 persons were initiated on RR-TB treatment, of whom $128(38 \%)$ were screened for SU using the ASSIST tool. Table 1 compared the clinical and demographic characteristics between those screened and those not screened. Of note, a significantly higher proportion of people initiated on treatment in the hospital did not undergo SU screening.

Table 1. Clinical and demographic characteristics for persons initiated on rifampicin-resistant tuberculosis (RR-TB) treatment from July 2018-September 2020 stratified by whether substance-use screening was conducted.

\begin{tabular}{ccccc}
\hline & $\begin{array}{c}\text { Total } \\
n=\mathbf{3 3 3}\end{array}$ & $\begin{array}{c}\text { Not Screened } \\
\boldsymbol{n}=\mathbf{2 0 5}\end{array}$ & $\begin{array}{c}\text { Screened } \\
\boldsymbol{n}=\mathbf{1 2 8}\end{array}$ & $p$-Value \\
\hline Male & $195(58.6)$ & $117(57.1)$ & $78(60.9)$ & 0.49 \\
\hline Median Age, years & $34(28-42)$ & $34(28-42)$ & $35(29-43)$ & 0.58 \\
\hline Age Category, years & & & & \\
$<20$ & $19(5.7)$ & $10(4.9)$ & $9(7.0)$ & \\
$20-29$ & $87(26.1)$ & $58(28.3)$ & $29(22.7)$ & \\
$30-39$ & $119(35.7)$ & $72(35.1)$ & $47(36.7)$ & \\
$40-49$ & $66(19.8)$ & $38(18.5)$ & $28(21.9)$ & 0.69 \\
$\geqslant 50$ & $42(12.6)$ & $27(13.2)$ & $15(11.7)$ & \\
\hline $\begin{array}{c}\text { Disease classification } \\
\text { Xpert MTB/RIF unconfirmed }\end{array}$ & $34(10.2)$ & $25(12.2)$ & $9(7.0)$ & \\
Rifampicin-mono resistance & $77(23.1)$ & $53(25.9)$ & $24(18.8)$ & \\
MDR including injectable & $191(57.4)$ & $113(55.1)$ & $78(60.9)$ & \\
resistance & $31(9.3)$ & $14(6.8)$ & $17(13.3)$ & 0.051 \\
MDR plus fluroquinolone \\
resistance
\end{tabular}


Table 1. Cont.

\begin{tabular}{|c|c|c|c|c|}
\hline & $\begin{array}{c}\text { Total } \\
n=333\end{array}$ & $\begin{array}{c}\text { Not Screened } \\
\quad n=205\end{array}$ & $\begin{array}{c}\text { Screened } \\
n=128\end{array}$ & $p$-Value \\
\hline \multicolumn{5}{|l|}{ Disease Site } \\
\hline Pulmonary TB & $314(94.3)$ & $194(94.6)$ & $120(93.8)$ & \\
\hline Extra-Pulmonary TB & $19(5.7)$ & $11(5.4)$ & $8(6.3)$ & 0.74 \\
\hline Site of Treatment initiation & $288(86.5)$ & $167(81.5)$ & $121(94.5)$ & \\
\hline $\begin{array}{l}\text { Primary Health Care Facility } \\
\text { Hospital }\end{array}$ & $45(13.5)$ & $38(18.5)$ & $7(5.5)$ & $0.001 *$ \\
\hline HIV Positive & $226(67.9)$ & $138(67.3)$ & $88(68.8)$ & 0.79 \\
\hline Median CD4 count & $79(28-239)$ & $73(24-217)^{\wedge}$ & $102(35-247)^{\wedge}$ & 0.30 \\
\hline On Antiretroviral Therapy & $218(96.5)$ & $132(95.7)$ & $86(97.7)$ & 0.38 \\
\hline
\end{tabular}

${ }^{*}$ Indicates statistical significance. ${ }^{\wedge} 30,23$, and 7 persons missing CD4 counts in the total, not screened and screened groups, respectively. Data are presented as number and proportions or medians and interquartile ranges.

\subsection{Substance Use Screening: Substances of Use and Risk Classification}

Of the 128 persons screened for $\mathrm{SU}, 88 \%(n=113 / 128)$ reported using substances. The median time from RR-TB treatment initiation to SU screening was 1.3 months (interquartile range [IQR] 0.5-3.5). Of persons screened, 65\% (83/128) reported moderate- or highrisk SU. Overall, $87 \%(n=72 / 83)$ of those with moderate- or high-risk SU received a brief intervention.

The reported substances of use (not mutually exclusive) and risk classification based on the ASSIST screening can be seen in Figure 2; the median number of substances used was 2 (IQR 1-2), with $61 \%(n=78 / 128)$ reporting $>1$ substance of use. Alcohol was the most frequently reported substance of use, with $80 \%(n=103 / 128)$ of those screened reporting alcohol use and $52 \%(n=54 / 103)$ reporting moderate- or high-risk alcohol use. Tobacco followed alcohol as the second most common substance of use with $65 \%(n=83 / 128)$ of persons screened reporting tobacco use and 39\% $(n=65 / 83)$ reporting moderate- or high-risk tobacco use.

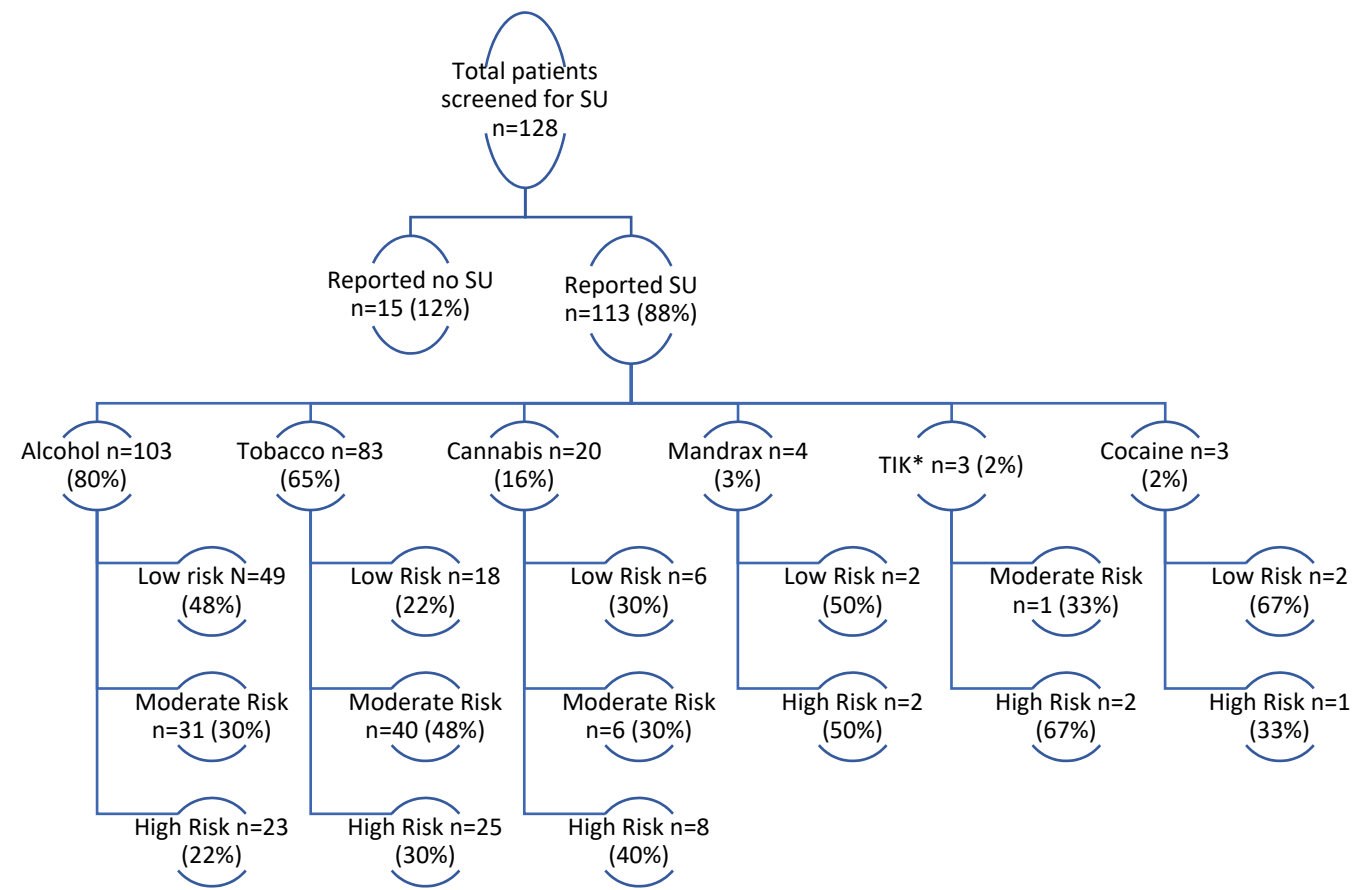

Figure 2. Substance-use screening outcomes among persons initiated on RR-TB treatment from July 2018-September 2020. * TIK= crystal methamphetamines. 
Among the 54 persons with moderate/high risk alcohol use, 17 (31\%) were initiated on naltrexone pharmacotherapy. None of the 17 persons initiated on naltrexone experienced any serious adverse events while still on therapy.

\subsection{Clinical and Demographic Characteristics Based on Highest Risk Classification}

Differences in the clinical and demographic characteristics based on the highest overall risk classification determined from the SU screening are shown in Table 2. Men, those 30-39 years of age, and those on antiretroviral therapy were significantly more like to have moderate/high risk SU $(p<0.05)$.

Table 2. Clinical and demographic characteristics of persons initiated on RR-TB treatment from July 2018-September 2020 who were screened for substance use, stratified by no- or low-risk SU and moderate- or high-risk SU.

\begin{tabular}{|c|c|c|c|c|}
\hline & $\begin{array}{l}\text { Total Screened } \\
\quad n=128\end{array}$ & $\begin{array}{c}\text { No-/Low-Risk SU } \\
n=45\end{array}$ & $\begin{array}{l}\text { Moderate-/High-Risk SU } \\
\qquad n=83\end{array}$ & $p$-Value \\
\hline Male & $78(60.9)$ & $14(31.1)$ & $64(77.1)$ & $<0.001 *$ \\
\hline Median Age, years & $35(29-43)$ & $34(25-47)$ & $35(30-42)$ & 0.64 \\
\hline \multicolumn{5}{|l|}{ Age Category, years } \\
\hline$<20$ & $9(7.0)$ & $5(11.1)$ & $4(4.8)$ & \\
\hline $20-29$ & $29(22.7)$ & $13(28.9)$ & $16(19.3)$ & \\
\hline $30-39$ & $47(36.7)$ & $11(24.4)$ & $36(43.4)$ & \\
\hline $40-49$ & $28(21.9)$ & $6(13.3)$ & $22(26.5)$ & \\
\hline$>=50$ & $15(11.7)$ & $10(22.2)$ & $5(6.0)$ & $0.006^{*}$ \\
\hline \multicolumn{5}{|l|}{ Time to SU screening } \\
\hline$<=2$ months & $77(60.2)$ & $32(71.1)$ & $45(54.2)$ & \\
\hline$>2$ months & $51(39.8)$ & $13(28.9)$ & $38(45.8)$ & 0.062 \\
\hline \multicolumn{5}{|l|}{ Disease classification } \\
\hline Xpert MTB/RIF unconfirmed & $9(7.0)$ & $3(6.7)$ & $6(7.2)$ & \\
\hline Rifampicin-mono resistance & $24(18.8)$ & $8(17.8)$ & $16(19.3)$ & \\
\hline MDR including injectable resistance & $78(60.9)$ & $25(55.5)$ & $53(63.9)$ & \\
\hline MDR plus fluroquinolone resistance & $17(13.3)$ & $9(20.0)$ & $8(9.6)$ & 0.43 \\
\hline \multicolumn{5}{|l|}{ Previous TB treatment history } \\
\hline None & $53(41.4)$ & $21(46.7)$ & $32(38.6)$ & \\
\hline Previous 1st line TB treatment & $66(51.6)$ & $20(44.4)$ & $46(55.4)$ & \\
\hline Previous 2nd line TB treatment & $9(7.0)$ & $4(8.9)$ & $5(6.0)$ & 0.48 \\
\hline \multicolumn{5}{|l|}{ Disease Site } \\
\hline Pulmonary TB & $120(93.8)$ & $42(93.3)$ & $78(94.0)$ & \\
\hline Extra-pulmonary TB & $8(6.3)$ & $3(6.7)$ & $5(6.0)$ & 0.89 \\
\hline \multicolumn{5}{|l|}{ Site of Treatment initiation } \\
\hline Primary Health Care Facility & $121(94.5)$ & $41(91.1)$ & $80(96.4)$ & \\
\hline Hospital & $7(5.5)$ & $4(8.9)$ & $3(3.6)$ & 0.21 \\
\hline HIV Positive & $88(68.8)$ & $29(64.4)$ & $59(71.1)$ & 0.44 \\
\hline Median CD4 count & $102(35-247)^{\wedge}$ & $100(35-238)$ & $107(38-257)^{\wedge}$ & 0.95 \\
\hline On Antiretroviral Therapy & $86(97.7)$ & $27(93.1)$ & $59(100.0)$ & 0.041 * \\
\hline
\end{tabular}

* Indicates statistical significance. ${ }^{\wedge} 7$ and 7 persons missing CD4 counts in the total screened and moderate-/highrisk SU groups, respectively. Data are presented as number and proportions or medians and interquartile ranges.

3.4. Rifampicin-Resistant Tuberculosis (RR-TB) Treatment Outcomes among Patients Screened for Substance Use Disorder within 2 Months of RR-TB Treatment Initiation

Of the 128 persons screened for SU, 77 were screened within 2 months of RR-TB treatment initiation and included in the outcome analysis. In total, $42 \%(n=32 / 77)$ had noor low-risk SU and 58\% $(n=45 / 77)$ had moderate- or high-risk SU. Of the 77 persons, $69 \%$, $12 \%$, and $12 \%$ had outcomes of treatment success, LTFU, and death, respectively. There 
were no significant differences in treatment outcomes between persons with no- or low-risk SU and those with moderate- or high-risk SU ( $p>0.05$, Table 3).

Table 3. RR-TB treatment outcomes for persons started on treatment from July 2018-September 2020 who were screened for substance use within 2 months of treatment initiation, stratified by no- or low-risk SU and moderate- or high-risk SU.

\begin{tabular}{|c|c|c|c|}
\hline & $\begin{array}{c}\text { Overall } \\
n=77 \\
n(\%)\end{array}$ & $\begin{array}{c}\text { No-/Low-Risk SU } \\
n=32 \\
n(\%)\end{array}$ & $\begin{array}{c}\text { Moderate/High Risk } \\
n=45 \\
n(\%)\end{array}$ \\
\hline Treatment Success & $53(68.8)$ & $21(65.6)$ & $32(71.1)$ \\
\hline Loss to Follow-up & $9(11.7)$ & $2(6.2)$ & 7 (15.6) \\
\hline Died & $9(11.7)$ & $5(15.6)$ & $4(8.9)$ \\
\hline Failed by Treatment & $3(3.9)$ & $3(9.4)$ & $0(0)$ \\
\hline Not Evaluated & $3(3.9)$ & $1(3.1)$ & $2(4.4)$ \\
\hline
\end{tabular}

Data are presented as numbers and proportions.

Of the 77 persons who received SBIRT and were included in the analysis of outcomes, 33 were eligible for naltrexone (had moderate or high risk SU). Of those, 11 were initiated on naltrexone therapy (Table 4). There were no significant differences in treatment outcomes based on whether or not naltrexone was received among this group ( $p>0.05$, Table 4$)$.

Table 4. RR-TB treatment outcomes for persons started on treatment from July 2018-September 2020 with moderate- or high-risk alcohol use who were screened for substance use within 2 months of treatment initiation, stratified by receipt of naltrexone.

\begin{tabular}{cccc}
\hline & $\begin{array}{c}\text { Overall } \\
\boldsymbol{n}=\mathbf{3 3} \\
\mathbf{( \% ,} \text { Column })\end{array}$ & $\begin{array}{c}\text { Did not Receive } \\
\text { Naltrexone } \\
\boldsymbol{n}=\mathbf{2 2}\end{array}$ & $\begin{array}{c}\text { Received Naltrexone } \\
\boldsymbol{n}=\mathbf{1 1}\end{array}$ \\
\hline Treatment Success & $23(69.7)$ & $16(72.7)$ & $7(63.6)$ \\
\hline Loss to Follow-up & $6(18.2)$ & $4(18.2)$ & $2(18.2)$ \\
\hline Died & $2(6.1)$ & $1(4.5)$ & $1(9.1)$ \\
\hline Not Evaluated & $2(6.1)$ & $1(4.5)$ & $1(9.1)$ \\
\hline
\end{tabular}

Data are presented as numbers and proportions.

\section{Discussion}

We report the results of the implementation of an SBIRT intervention among a cohort of people living with RR-TB in Khayelitsha receiving care in the primary health care setting between 2018 and 2020. Of the 333 people who started RR-TB treatment in Khayelitsha during the study period, just over a third (128) received this SBIRT intervention. While it was the intention that the services be offered to everyone, the programmatic conditions meant that most people with RR-TB did not receive the intervention. Persons initiated on treatment in Khayelitsha at the primary health-care level were more likely to have received the SBIRT compared to persons initiating treatment at the hospital level, due to the fact that this SBIRT package was only implemented at primary health-care facilities.

The low coverage of SBIRT reflects some of the implementation challenges associated with this program. The majority of the screening was done by RR-TB counselors who moved between 10 primary health care facilities. These counselors sometimes experienced logistical challenges when coordinating being at the clinic at the same time as the patient's routine clinical appointment. This highlights the importance of having staff stationed at primary health care facilities trained on SBIRT so as to minimize missed opportunities at routine RR-TB clinical visits [22]. Although the TB nurses stationed at the primary health-care facilities were also trained on the SBIRT intervention, few administered this 
intervention due to competing clinical priorities, and lack of a private space to consult with the patient. This highlights the importance of the SBIRT package being implemented with adequate human resources and appropriate cadres of staff [23-25]. In our setting we found that lay counselors had fewer competing clinical priorities than nurses or doctors and were key in the implementation of these SBIRT services. In other settings, community health workers have also been used successfully to implement SBIRT and are a promising cadre of staff to involve in substance-use services [26].

Overall, reported rates of SU were high among those screened, with more than $60 \%$ of participants who underwent screening reporting moderate- or high-risk SU. This rate is higher than that reported in other cohorts [27]. The most common substances used were alcohol and tobacco. Moderate-/high-risk SU was more common among males, persons between the ages of 30-39 years, and persons on antiretroviral treatment; however the latter association is likely to be a statistical artifact. Although the high rates of SU seen in this cohort suggest SBIRT should be offered to all persons undergoing treatment for RR-TB, urgent implementation could be prioritized among these groups.

Our study did not reveal any statistically significant differences in RR-TB treatment outcomes when stratified by SU risk score. There may be several reasons for this, including the relatively small sample size and the relatively ubiquitous nature of SU reported among those screened. It may also be that the SBIRT intervention component had some impact on the ability of persons to remain engaged in care, although this would need to be assessed in a more formal study. Supporting this hypothesis, we note that the rates of treatment success in our cohort are $69 \%$, higher than those historically reported nationally and in the Khayelitsha setting $[1,16,28]$. Some of this may be due to the expanded use of the shorter and more effective treatment regimens that have been rolled out in South Africa. However, the fact that such improved outcomes were also registered among persons with moderate/high SU in our cohort is encouraging. We do note that among those who reported moderate/high-risk SU, rates of LTFU remained unacceptably high at $16 \%$. While not reaching statistical significance, the difference in LTFU rates among those with moderate/high risk SU compared to no/low substance use supports the fact that more work is needed to identify and support persons with comorbid RR-TB and substance use disorders.

We aimed to assess the use of naltrexone therapy as possible therapeutic intervention in those persons with moderate-/high-risk alcohol use on RR-TB treatment outcomes, as this has not previously been described [29]. However, uptake in our study was low with approximately one third of those who were eligible accessing therapy. One reason for this may be that naltrexone was available only through a medical practitioner and thus required an extra visit where the person conducting the SBIRT was a counselor. When implementing such interventions in future it will be important to ensure that naltrexone is available at the same time that the SBIRT is conducted. Also, persons with RR-TB are on a number of medications; additional tablets may be less acceptable to persons than those in other contexts on fewer concomitant medications. The low uptake greatly limited our ability to assess the utility of naltrexone use and could account for the fact that we did not see any significant association between naltrexone use and treatment outcomes. It was encouraging, however, that there were no serious adverse events reported among people on RR-TB treatment while on naltrexone, although more rigorous data is needed.

This retrospective study had a number of important limitations. Firstly, there was a small sample size, with only $38 \%$ of persons treated for RR-TB accessing this intervention. This impacted the ability to detect significant differences between the various groups of RRTB patients evaluated, and may have led to selection bias. Despite efforts to systematically offer SBIRT to all persons with RR-TB, health center staff may have been more likely to offer this intervention to persons with SU challenges, which may have resulted in a higher rate of SU seen in our cohort than in the overall population of people started on RR-TB treatment in Khayelitsha during the study period. Also, persons with a more significant alcohol use disorder are likely to have preferentially received naltrexone therapy and this may have 
influenced the treatment outcomes observed. Additionally, persons in hospitals, or persons with RR-TB with early mortality were less likely to receive the SBIRT package, which may have led to bias in treatment outcome results. Finally, this analysis was conducted in a single district which may limit the generalizability of our findings.

\section{Conclusions}

In spite of these limitations, our study has several important findings. First, SU is extremely common among persons with RR-TB and there is a need for interventions to screen for and address this co-morbidity as part of "person-centered care". Second, while a SBIRT intervention can be implemented in the outpatient setting among people living with RR-TB, there is a need for dedicated staff and resources to do this work in order to reach the entire population. Third, among people with SU, good treatment outcomes can be achieved-although rates of LTFU still remain unacceptably high among those with moderate or high-risk SU scores. Integrated, holistic care is needed at the community level for persons with RR-TB and our study shows that such care needs to include services to addresses the unique challenges that persons with RR-TB who use substances face.

Author Contributions: Conceptualization, A.R., B.B., E.R., H.R., J.F. and E.M.-H.; methodology, A.R., E.M.-H., P.I., J.D. and J.F.; software, E.M.-H. and J.D.; validation, E.M.-H. and J.D.; formal analysis, E.M.-H.; investigation, A.R., B.B., B.M. and E.R.; resources, A.R., B.M. and E.R.; data curation, E.M.-H., J.D., A.R., E.R., B.B. and B.M.; writing-original draft preparation, E.M.-H., A.R. and J.F.; writing-review and editing, A.R., B.B., B.M., J.F., J.D., E.R., H.R., L.W., P.I., E.v.d.H., Y.K., E.M.-H.; visualization, E.M.-H.; supervision, A.R., B.M., E.R., E.M.-H.; project administration, A.R., B.B., B.M. and E.R.; funding acquisition, A.R. All authors have read and agreed to the published version of the manuscript.

Funding: This research received no external funding.

Institutional Review Board Statement: Ethical approval was obtained from the University of Cape Town Human Research Ethics Committee (HREC 499/2011) for this study. Additionally, this research fulfilled the exemption criteria set by the MSF Ethical Review Board for a posterior analysis of routinely collected clinical data and thus did not require MSF ERB review.

Informed Consent Statement: Patient consent was waived due to the retrospective nature of this study.

Data Availability Statement: Data is available from the corresponding author upon request.

Acknowledgments: The authors would like to thank the Cape Town City Health Department, the Provincial Government of the Western Cape, and National TB Program for supporting and managing the SU RR-TB program. Importantly, the authors would like to acknowledge Médecins Sans Frontières staff involved in implementation activities and people living with RR-TB in Khayelitsha.

Conflicts of Interest: The authors declare no conflict of interest.

\section{References}

1. World Health Organization (WHO). Global Tuberculosis Report 2021. Available online: https://www.who.int/publications/i/ item/9789240037021 (accessed on 1 November 2021).

2. Ahmad, N.; Ahuja, S.D.; Akkerman, O.W.; Alffenaar, J.C.; Anderson, L.F.; Baghaei, P.; Bang, D.; Barry, P.M.; Bastos, M.L.; Behera, D.; et al. Collaborative Group for the Meta-Analysis of Individual Patient Data in MDR-TB treatment-2017. Lancet 2018, 392, 821-834. [CrossRef]

3. Law, S.; Daftary, A.; O’Donnell, M.; Padayatchi, N.; Calzavara, L.; Menzies, D. Interventions to improve retention-in-care and treatment adherence among patients with drug-resistant tuberculosis: A systematic review. Eur. Respir. J. 2018, 53, 1801030. [CrossRef] [PubMed]

4. Shean, K.; Streicher, E.; Pieterson, E.; Symons, G.; van Zyl-Smit, R.; Theron, G.; Lehloenya, R.J.; Padanilam, X.; Wilcox, P.; Victor, T.C.; et al. Drug-Associated Adverse Events and Their Relationship with Outcomes in Patients Receiving Treatment for Extensively Drug-Resistant Tuberculosis in South Africa. PLoS ONE 2013, 8, e63057. [CrossRef]

5. Morris, M.D.; Quezada, L.; Bhat, P.; Moser, K.; Smith, J.; Perez, H.; Laniado-Laborin, R.; Estrada-Guzman, J.; Rodwell, T.C. Social, economic, and psychological impacts of MDR-TB treatment in Tijuana, Mexico: A patient's perspective. Int. J. Tuberc. Lung Dis. 2013, 17, 954-960. [CrossRef] 
6. Isaakidis, P.; Rangan, S.; Pradhan, A.; Ladomirska, J.; Reid, T.; Kielmann, K. 'I cry every day': Experiences of patients co-infected with HIV and multidrug-resistant tuberculosis. Trop. Med. Int. Health 2013, 18, 1128-1133. [CrossRef]

7. Gelmanova, I.; Keshavjee, S.; Golubchikova, V.; Berezina, V.; Strelis, A.; Yanova, G.; Atwood, S.; Murray, M. Barriers to successful tuberculosis treatment in Tomsk, Russian Federation: Non-adherence, default and the acquisition of multidrug resistance. Bull. World Health Organ. 2007, 85, 703-711. [CrossRef]

8. Holtz, T.H.; Lancaster, J.; Laserson, K.F.; Wells, C.D.; Thorpe, L.; Weyer, K. Risk factors associated with default from multidrugresistant tuberculosis treatment, South Africa, 1999-2001. Int. J. Tuberc. Lung Dis. 2006, 10, 649-655.

9. Baddeley, A. A Systematic Literature Review to Assess the Impact of Alcoholism on Tuberculosis Control and Strategies to Encourage Compliance Amongst Alcoholic TB Patients. Master's Thesis, University of London, London, UK, 2008.

10. Kendall, E.A.; Theron, D.; Franke, M.F.; Van Helden, P.; Victor, T.C.; Murray, M.B.; Warren, R.M.; Jacobson, K.R. Alcohol, Hospital Discharge, and Socioeconomic Risk Factors for Default from Multidrug Resistant Tuberculosis Treatment in Rural South Africa: A Retrospective Cohort Study. PLoS ONE 2013, 8, e83480. [CrossRef]

11. Ngouleun, W.; Nya, P.C.B.; Pieme, A.C.; Telefo, P.B.; Williams, N.; Prosper, B.N.; Anatole, P.C.; Bruno, T.P. Risk assessment of hepatotoxicity among tuberculosis and human immunodeficiency virus / AIDS-coinfected patients under tuberculosis treatment. Int. J. Mycobacteriol. 2016, 5, 482-488. [CrossRef]

12. World Health Organization (WHO). Brief Intervention: The ASSIST-Linked Brief Intervention for Hazardous and Harmful Substance Use: Manual for Use in Primary Care. Available online: https:/ /www.who.int/publications/i/item/the-assist-linkedbrief-intervention-for-hazardous-and-harmful-substance-use (accessed on 1 November 2021).

13. World Health Organization (WHO). Management of Substance Dependence Review Series: A Systematic Review of Opioid Antagonists for Alcohol Dependence. Available online: https://www.who.int/substance_abuse/publications/en/opioid.pdf (accessed on 1 November 2021).

14. Srisurapanont, M.; Jarusuraisin, N. Opioid antagonists for alcohol dependence. Cochrane Database Syst. Rev. 2005, 1, CD001867. [CrossRef]

15. Cape Town City Health. City of Cape Town-2011 Census-Khayelitsha Health District. Available online: https://resource. capetown.gov.za/documentcentre/Documents/Maps\%20and\%20statistics/Khayelitsha\%20Health\%20District.pdf (accessed on 1 November 2021).

16. Cox, H.; Hughes, J.; Daniels, J.; Azevedo, V.; McDermid, C.; Poolman, M.; Boulle, A.; Goemaere, E.; Van Cutsem, G. Communitybased treatment of drug-resistant tuberculosis in Khayelitsha, South Africa. Int. J. Tuberc. Lung Dis. 2014, 18, 441-448. [CrossRef] [PubMed]

17. University of Cape Town. A Mixed-Methods Study of the Nature and Extent of the Alcohol Trade in Khayelitsha-And Community Perceptions. Available online: https://movendi.ngo/wp-content/uploads/2020/04/khayelitsha_-_alcohol_trade_ and_community_perceptions_report.pdf (accessed on 1 November 2021).

18. Peltzer, K.; Phaswana-Mafuya, N. Drug use among youth and adults in a population-based survey in South Africa. S. Afr. J. Psychiatry 2018, 24, 1139. [CrossRef] [PubMed]

19. Sinclair, J.D. Evidence about the use of naltrexone and for different ways of using it in the treatment of alcoholism. Alcohol Alcohol. 2001, 36, 2-10. [CrossRef] [PubMed]

20. World Health Organization (WHO). Definitions and Reporting Framework for Tuberculosis-2013 Revision. Available online: http:/ /apps.who.int/iris/handle/10665/79199 (accessed on 1 November 2021).

21. REDCap. Research Electronic Data Capture: REDCap. Available online: https://projectredcap.org/software/ (accessed on 1 November 2021).

22. Jonas, D.E.; Garbutt, J.C.; Brown, J.M.; Amick, H.R.; Brownley, K.A.; Council, C.L.; Viera, A.J.; Wilkins, T.M.; Schwartz, C.; Richmond, E.M.; et al. Screening, Behavioral Counseling, and Referral in Primary Care to Reduce Alcohol Misuse. Comp. Eff. Rev. 2012, 64, 1-87.

23. van der Westhuizen, C.; Malan, M.; Naledi, T.; Roelofse, M.; Myers, B.; Stein, D.J.; Lahri, S.; Sorsdahl, K. Patient outcomes and experience of a task-shared screening and brief intervention service for problem substance use in South African emergency centres: A mixed methods study. Addict. Sci. Clin. Pract. 2021, 16, 31. [CrossRef]

24. Madhombiro, M.; Kidd, M.; Dube, B.; Dube, M.; Mutsvuke, W.; Muronzie, T.; Zhou, D.T.; Derveeuw, S.; Chibanda, D.; Chingono, A.; et al. Effectiveness of a psychological intervention delivered by general nurses for alcohol use disorders in people living with HIV in Zimbabwe: A cluster randomized controlled trial. J. Int. AIDS Soc. 2020, 23, e25641. [CrossRef]

25. Calligaro, G.L.; de Wit, Z.; Cirota, J.; Orrell, C.; Myers, B.; Decker, S.; Stein, D.J.; Sorsdahl, K.; Dawson, R. Brief psychotherapy administered by non-specialised health workers to address risky substance use in patients with multidrug-resistant tuberculosis: A feasibility and acceptability study. Pilot Feasibility Stud. 2021, 7, 28. [CrossRef]

26. Wennerstrom, A.; Hargrove, L.; Minor, S.; Kirkland, A.L.; Shelton, S.R. Integrating Community Health Workers Into Primary Care to Support Behavioral Health Service Delivery. J. Ambul. Care Manag. 2015, 38, 263-272. [CrossRef]

27. Necho, M.; Tsehay, M.; Seid, M.; Zenebe, Y.; Belete, A.; Gelaye, H.; Muche, A. Prevalence and associated factors for alcohol use disorder among tuberculosis patients: A systematic review and meta-analysis study. Subst. Abus. Treat. Prev. Policy 2021, 16, 2. [CrossRef] 
28. Mohr-Holland, E.; Reuter, A.; Hughes, J.; Daniels, J.; Beko, B.; Makhanda, G.; De Avezedo, V.; Kock, Y.; Cox, H.; Furin, J.; et al. Correspondence regarding "Delamanid for rifampicin-resistant tuberculosis: A retrospective study from South Africa". Eur. Respir. J. 2020, 56, 2000837. [CrossRef]

29. Shin, S.; Livchits, V.; Connery, H.S.; Shields, A.; Yanov, S.; Yanova, G.; Fitzmaurice, G.M.; Nelson, A.K.; Greenfield, S.F. Tomsk Tuberculosis Alcohol Working Group Effectiveness of alcohol treatment interventions integrated into routine tuberculosis care in Tomsk, Russia. Addiction 2013, 108, 1387-1396. [CrossRef] [PubMed] 